\title{
Comparative Study of the Efficacy of the Lysozyme, Benzydamine and Chlorhexidine Oral Spray in the Treatment of Acute Tonsillopharyngitis - Results of a Pilot Study
}

\author{
Nataša Golac-Guzina ${ }^{1}$, Zorica Novaković ${ }^{1}$, Zehra Sarajlić ${ }^{2}$, Aziz Šukalo ${ }^{3}$, Jasna \\ Džananović ${ }^{3}$, Una Glamočlija ${ }^{3,4}$, Belma Kapo ${ }^{3}$, Vedina Čordalija ${ }^{5}$, Meliha Mehić ${ }^{3}$
}

${ }^{1}$ University Clinical Center of the Republic of Srpska, ENT Clinic, Banjaluka, Bosnia and Herzegovina, ${ }^{2}$ University Clinical Center Sarajevo, Sarajevo, Bosnia and Herzegovina, ${ }^{3}$ Bosnalijek JSC, Sarajevo, Bosnia and Herzegovina, ${ }^{4}$ School of Medicine, University of Mostar, Mostar, Bosnia and Herzegovina, ${ }^{5}$ Psychiatric hospital of Canton Sarajevo - Clinical Pharmacy, Bosnia and Herzegovina

\author{
Correspondence: \\ meliha.mehic@bosnalijek.com \\ Tel.: + 38733254596 \\ Fax.: + 38733814250
}

Received: 29 September 2018

Accepted: 21 February 2019

Key Words: Sore Throat - Antiseptics * Lysozyme.

\section{Introduction}

Acute tonsillopharyngitis is among the most common infections in adults, and it is the second most common reason for visiting a doctor (1). Although it is a self-limiting condition, patients usually seek help for the immediate relief of symptoms such as pain, difficulty in swallowing and the throat swelling.
Objective. Lysozyme is a natural antimicrobial and immunomodulatory enzyme, which is produced as a host response to infectious agents. The objective of this study was to compare the efficacy and safety of lysozyme-based versus benzydamine and chlorhexidinebased oral spray in patients with an acute tonsillopharyngitis associated with a common cold. Patients and Methods. A prospective twoarm pilot study (lysozyme/cetylpyridinium/lidocaine spray versus: benzydamine spray-arm 1; chlorhexidine/lidocaine spray-arm 2) was conducted in the primary health care unit. Efficacy was evaluated by the patient's self-assessment of pain, difficulty in swallowing and the throat swelling, by using the visual analog scale (VAS) at baseline and three follow-up visits. Safety was evaluated by the assessment of the frequency and severity of adverse effects. Results. Lysozyme-based spray reduced pain faster than benzydamine-based spray and slower than chlorhexidine-based spray. Lysozyme-based and chlorhexidinebased sprays similarly reduced difficulty in swallowing, but were faster than benzydamine-based spray. Similar effects on the reduction of throat swelling were seen in all treated groups. All tested products showed proper safety and were well tolerated, with no serious adverse events reported. Conclusions. The lysozyme-based oral spray was shown to be effective and safe in the reduction of pain, difficulty in swallowing and throat swelling in patients with acute tonsillopharyngitis associated with a common cold. Lysozyme-based oral spray (containing natural compound with advantages of influencing immune system and preventing recurrences) had similar activity to benzydamine and chlorhexidine-based oral antiseptic sprays.

Viruses are responsible for $85-95 \%$ of acute tonsillopharyngitis cases in adults. In contradiction with the European guidelines for the treatment of acute viral tonsillopharyngitis, the antibiotic treatments are still inappropriately prescribed (2). Moreover, acute tonsillopharyngitis is, along with otitis and sinusitis, the leading cause of prescribing antibiotics in the world (2). Unreason- 
able prescribing of antibiotics increases the risk of bacterial resistance, a stumbling block in the modern health care system (2, $3)$. Being the frequent indication for prescription of antibiotics, treatment of acute tonsillopharyngitis significantly contributes to an increase of antimicrobial resistance and treatment costs (4).

In the absence of complications, such as bacterial superinfection, symptoms of acute tonsillopharyngitis can be successfully reduced using local symptomatic treatment (5). Moreover, many over-thecounter (OTC) drugs, such as lysozyme, cetylpyridinium, lidocaine, benzydamine, and chlorhexidine, are available today for the topical treatment of those patients. Oral antiseptics are characterized by direct effects on viral and inflammatory causes, enabling reduction of local pain, rapid onset of action, efficacy and an excellent safety profile in the treatment of acute tonsillopharyngitis (6). Those preparations usually come in the form of sprays, solutions for gargling and lozenges or oriblettes that are applied directly to the mouth or throat mucosa, and are frequently used in the symptomatic treatment of acute uncomplicated cases of tonsillopharyngitis (6-9).

The available data from the comparative clinical trials, mainly placebo-controlled trials, indicate the efficacy and safety of benzydamine-based and chlorhexidine-based oral antiseptics in the topical treatment of acute pharyngitis associated with common cold (7, $8,10,11)$. However, the data regarding the comparison of lysozyme-based versus benzydamine-based and chlorhexidine-based antiseptics in the form of oral spray are limited.

The objective of this pilot study was to compare the efficacy and safety of antiseptics in the form of the oral spray (lysozymebased versus benzydamine-based spray, and lysozyme-based versus chlorhexidine-based spray) in patients with an acute tonsillopharyngitis associated with a common cold.

\section{Patients and Methods}

\section{Study Design and Data Collection}

Prospective, two-arm pilot study was conducted in patients with an acute tonsillopharyngitis associated with a common cold. Patients aged 18 years and older with symptoms of acute tonsillopharyngitis which was confirmed at the baseline visit by clinical findings and symptoms on the expanded 21-point Tonsillo-Pharyngitis Assessment (TPA) were recruited in the study in the primary health care unit. Patients were assigned to one of two study arms, i.e. one of two antiseptics. In the first study arm, patients treated with lysozyme/cetylpyridinium/lidocaine oral spray (Lysobact COMPLETE Spray, Bosnalijek JSC Sarajevo, Bosnia and Herzegovina) were compared to patients treated with benzydamine oral spray, while in the second study arm, patients treated with lysozyme/ cetylpyridinium/oral lidocaine spray were compared to patients treated with chlorhexidine/lidocaine oral spray. Concomitant therapy with analgesics, antiinflamatory and antimicrobic drugs were considered exclusion criteria.

\section{Ethics Statement}

Medicines \& Medical Devices Agency of Bosnia and Herzegovina approved the study. All procedures were made by following the Helsinki Declaration from 1975 and its amendments from 1983.

\section{Evaluation of Efficacy and Safety}

Efficacy of local antiseptics was evaluated by analyzing the visual analog scale (VAS) filled out by the patient for the self-assessment of pain, difficulty in swallowing and the throat swelling. Safety was evaluated based on the frequency and severity of the adverse effects of local antiseptics. 


\section{Data Collection}

The data were collected during the baseline visit and three follow-up visits, at Day 2, Day 3 and Day 5. The data collected at the baseline visit were: general aspect, TPA score (oral temperature, oropharyngeal color, size of tonsils, number of oropharyngeal exanthemas, largest size of anterior cervical lymph nodes, number of anterior cervical lymph nodes, maximum tenderness of some anterior cervical lymph nodes), VAS assessment of pain, difficulty in swallowing and the throat swelling. The data collected at each follow-up visits were: general aspect, VAS assessment of pain, difficulty in swallowing and the throat swelling and the data on the adverse effects.

\section{Statistical Analysis}

Normality of quantitative variables distribution was assessed by Kolmogorov-Smirnov test. The significance of the relationship between two categorical variables was analyzed with $\chi^{2}$ test. The significance of differences between groups for non-normally distributed variables was assessed using Mann-Whitney $\mathrm{U}$ test. Friedmans test was used to detect differences in treatments across multiple test attempts and the difference between baseline and follow up visit was tested using Wilcoxon signed-rank test. The statistically significant level was defined as $\mathrm{P}<0.05$. Statistical analyses were performed using SPSS 23.0 package (SPSS Inc., Chicago, IL, USA).

\section{Results}

In the first study arm, out of 36 patients included, 4 patients were excluded because of the need to include antibiotic or analgesic therapy. Finally, 15 patients were treated with lysozyme-based spray and 17 patients with benzydamine based spray. Demographic characteristics and TPA score of patients in the first study arm are presented in Table 1.

In the paired efficacy analysis (Table 2), a significant reduction in all VAS scores (pain, difficulty in swallowing, throat swelling) for both medicines (lysozyme vs benzydamine based products) (Friedman's test, $\mathrm{P}<0.001$ ) was shown. Both products showed proper safety and were well tolerated, with no serious adverse events reported.

Demographic characteristics and TPA scores of patients in the second study arm are presented in Table 3. In the second study arm, out of 36 patients included, 5 patients were excluded because of the need to include antibiotic or analgesic therapy. Finally, 17 patients were treated with lysozyme-based spray and 14 patients with chlorhexidinebased spray.

In the paired efficacy analysis (Table 4), a significant reduction in all VAS scores (pain, difficulty in swallowing, throat swelling) for both medicines (lysozyme vs chlorhexidinebased products) (Friedman's test, $\mathrm{P}<0.001$ ) was shown. No serious adverse events were recorded, and both products were considered safe and well tolerated.

Table 1. Demographic Characteristics and Tonsillo-Pharyngitis Assessment Scores of Patients Treated with Lysozyme/Cetylpyridinium/Lidocaine Spray and Bezydamine Spray

\begin{tabular}{llll}
\hline \multirow{2}{*}{ Characteristics } & Treatment & & \\
\cline { 2 - 4 } & Lysozyme/cetylpyridinium/Lidocaine spray & Benzydamine & $\mathrm{P}$ \\
\hline Gender, female [n (\%)] & $8(53.3)$ & $11(64.7)$ & $0.513^{*}$ \\
\hline Age, (years, median, min- max) & $36(18-93)$ & $40(20-75)$ & $0.151^{*}$ \\
\hline TPA score median (min-max) & $5(3-10)$ & $6(1-11)$ & $0.710^{\dagger}$ \\
\hline
\end{tabular}

${ }^{*}$ Chi square test; ${ }^{\dagger}$ Mann-Whitney U test; TPA=Tonsillo-Pharyngitis Assessment. 
Table 2. Comparison of Visual Analog Scale Scores of Pain, Difficulty in Swallowing and the Throat Swelling Between Lysozyme/Cetylpyridinium/Lidocaine Spray and Benzydamine Spray at Baseline and Follow-Up Visits

\begin{tabular}{|c|c|c|c|c|c|}
\hline \multirow{3}{*}{ VAS } & \multirow{3}{*}{ Visit } & \multicolumn{4}{|l|}{ Treatment } \\
\hline & & \multicolumn{2}{|c|}{ Lysozyme/cetylpyridinium/ lidocaine } & \multicolumn{2}{|l|}{ Benzydamine } \\
\hline & & Median (min-max) & $\mathrm{P}^{*}$ & Median (min-max) & $\mathrm{P}^{*}$ \\
\hline \multirow{4}{*}{ Pain } & Baseline & $4.0(1-6)$ & \multirow{4}{*}{$<0.001$} & $2.2(0-7)$ & \multirow{4}{*}{$<0.001$} \\
\hline & Day 2 & $3.0(1-4)^{* * *}$ & & $2.2(0-5)$ & \\
\hline & Day 3 & $1.0(0-3)^{* *}$ & & $1.4(0-4)^{* *}$ & \\
\hline & Day 5 & $0.5(0-1)^{* *}$ & & $1.0(0-2)^{* *}$ & \\
\hline \multirow{4}{*}{$\begin{array}{l}\text { Difficulty in } \\
\text { swallowing }\end{array}$} & Baseline & $3.2(1-6)$ & \multirow{4}{*}{$<0.001$} & $2.3(0-7)$ & \multirow{4}{*}{$<0.001$} \\
\hline & Day 2 & $2.5(1-5)^{* *}$ & & $2.3(0-5)$ & \\
\hline & Day 3 & $1.0(0-3)^{* *}$ & & $1.1(0-3)^{* *}$ & \\
\hline & Day 5 & $0.0(0-3)^{* *}$ & & $0.6(0-1.5)^{* *}$ & \\
\hline \multirow{4}{*}{ Throat swelling } & Baseline & $4.0(1-7)$ & \multirow{4}{*}{$<0.001$} & $1.9(0-6)$ & \multirow{4}{*}{$<0.001$} \\
\hline & Day 2 & $2.0(0-6)^{* *}$ & & $0.7(0-4)^{* *}$ & \\
\hline & Day 3 & $0.50(0-3)^{* *}$ & & $0.0(0-2)^{* *}$ & \\
\hline & Day 5 & $0.0(0-3)^{* *}$ & & $1.0(0-1)^{* *}$ & \\
\hline
\end{tabular}

VAS=Visual analog scale; *Friedman's test; **Wilcoxon test (follow up visit vs. baseline) $\mathrm{P}<0.05$.

Table 3. Demographic Characteristics and Tonsillo-Pharyngitis Assessment (TPA) Scores of Patients Treated with Lysozyme/Cetylpyridinium/Lidocaine Spray and Chlorhexidine/Lidocaine Spray

\begin{tabular}{llll}
\hline \multirow{2}{*}{ Characteristics } & \multicolumn{2}{l}{ Treatment } & P \\
\cline { 2 - 4 } & Lysozyme/cetylpyridinium/lidocaine spray & Chlorhexidine/lidocaine spray & $0.052^{*}$ \\
\hline Gender, female, $\mathrm{n}(\%)$ & $12(70.6)$ & $5(35.7)$ & $0.003^{\ddagger}$ \\
\hline Age, years, median, (min-max) & $37(27-68)$ & $53.5(29-81)$ & $0.092^{\ddagger}$ \\
\hline TPA score, median (min-max) & $4(1-16)$ & $6.5(3-14)$ & \\
\hline
\end{tabular}

"Chi square test; ${ }^{*}$ Mann-Whitney U test. TPA=Tonsillo-Pharyngitis Assessment.

Table 4. Comparison of Visual Analog Scale (VAS) Scores of Pain, Difficulty in Swallowing and the Throat Swelling Between Lysozyme/Cetylpyridinium/Lidocaine Spray and Chlorhexidine/Lidocaine Spray at Baseline and at Follow-Up Visits

\begin{tabular}{|c|c|c|c|c|c|}
\hline \multirow{3}{*}{ VAS } & \multirow{3}{*}{ Visit } & \multicolumn{4}{|l|}{ Treatment } \\
\hline & & \multirow{2}{*}{$\begin{array}{l}\text { Lysozyme/cetylpyridinium/ Lidocaine spray } \\
\text { Median (min-max) }\end{array}$} & \multicolumn{3}{|c|}{ Chlorhexidine/Lidocaine spray } \\
\hline & & & $\mathrm{P}^{*}$ & Median (min-max) & $\mathrm{P}^{*}$ \\
\hline \multirow{4}{*}{ Pain } & Baseline & $3.0(0-7)$ & \multirow{4}{*}{$<0.001$} & $3.6(1-6.5)$ & \multirow{4}{*}{$<0.001$} \\
\hline & Day 2 & $3.0(0-4.7)$ & & $3.25(1-5.9)^{* *}$ & \\
\hline & Day 3 & $1.5(0-3.3)^{* * *}$ & & $2.0(0-5)^{* *}$ & \\
\hline & Day 5 & $0.0(0-1.6)^{* * *}$ & & $0.5(0-2.6)^{* *}$ & \\
\hline \multirow{4}{*}{$\begin{array}{l}\text { Difficulty in } \\
\text { swallowing }\end{array}$} & Baseline & $3.4(0-6.7)$ & \multirow{4}{*}{$<0.001$} & $3.35(1-6)$ & \multirow{4}{*}{$<0.001$} \\
\hline & Day 2 & $2.8(0.5-0.5)^{* * *}$ & & $3.0(1-6)^{* *}$ & \\
\hline & Day 3 & $1.3(0-3)^{* *}$ & & $1.9(0-5)^{* *}$ & \\
\hline & Day 5 & $0.0(0-1.6)^{* * *}$ & & $0.5(0-2.6)^{* *}$ & \\
\hline \multirow{4}{*}{ Throat swelling } & Baseline & $2.0(0-6.3)$ & \multirow{4}{*}{$<0.001$} & $2.5(0-7)$ & \multirow{4}{*}{$<0.001$} \\
\hline & Day 2 & $2.0(0-3.5)$ & & $2.5(0-5.4)$ & \\
\hline & Day 3 & $0.0(0-3)^{* * *}$ & & $1.25(0-5)^{* *}$ & \\
\hline & Day 5 & $0.0(0-1.6)^{* * *}$ & & $0.0(0-2)^{* *}$ & \\
\hline
\end{tabular}

VAS=Visual analog scale; "Friedman's test; "Wilcoxon test (follow up visit vs. baseline) $\mathrm{P}<0.05$. 


\section{Discussion}

To our knowledge, this is the first study to compare lysozyme-based and other antiseptics in the form of oral sprays in patients with acute tonsillopharyngitis associated with a common cold. The lysozyme-based oral spray was shown to be effective and safe in the reduction of pain, difficulty in swallowing and throat swelling.

In the reduction of pain, lysozyme-based oral spray showed the faster onset of action compared to benzydamine-based spray, but delayed onset of action compared to chlorhexidine-based spray. In the reduction of difficulty in swallowing, lysozyme-based oral spray was similar to chlorhexidinebased spray but showed faster onset of action compared to benzydamine-based spray. In the reduction of throat swelling, the similar results were obtained for all treatments (lysozyme, benzydamine and chlorhexidine-based sprays).

Lysozyme, an antiseptic, is also known to have antibiotic and antiviral effects (12). Additionally, as a natural enzyme, it has an overall role in the body justifying the name - "enzyme of the future" (13). Unlike other antiseptics, in addition to its anti-inflammatory activity, lysozyme possess immunomodulatory activity. As an integral component of natural cells of the immune system, it is one of the most critical elements of the local non-specific microbial resistance of the mucosa. This is supported by the fact that the levels of immunoglobulins and lysozyme correlate (13). Also, studies demonstrated the efficacy of lysozyme-based preparations in the local treatment of pharyngitis and tonsillitis in children and adults (10, 14). According to a study with the patient reported outcomes, an oral spray containing the combination of lysozyme-chloride and cetylpyridinium-chloride could quickly, efficiently and safely solve the acute symptoms of tonsillopharyngitis associated with common cold (9). In the treatment of a sore throat, the local symptomatic therapy aims primarily to reduce the pain (6), and the pain reduction is usually the primary outcome of clinical trials testing the efficacy of different treatments for a sore throat (15). However, besides pain reduction, the impact of additional beneficial effects such as antiinflammatory, immunomodulatory, proregenerative should influence the choice of optimal therapy. Therefore, lysozyme based preparations open new perspectives in the treatment of those patients.

Benzydamine is a locally-acting nonsteroidal anti-inflammatory drug with local anesthetic and analgesic properties. It is widely used in the symptomatic treatment of pain, irritation and other symptoms of inflammation of the oropharynx (8). Although benzydamine in the form of oral rinse showed the more significant reduction of pain and dysphagia compared to placebo in patients with viral pharyngitis or tonsillitis (16), in our study, in the form of the oral spray, it showed slower efficacy in reduction of difficulties in swallowing when compared to lysozyme-based spray.

In concordance with our results, chlorhexidine-based antiseptic in the form of lozenges was effective in the treatment of a sore throat in patients with upper respiratory infection (17). In the form of an oral spray, chlorhexidine-lidocaine was also as effective and safe as a product based on echinacea and sage (18). In a study that compared the efficacy of benzydamine oral spray and chlorhexidine oral spray for the treatment of streptococcal tonsillopharyngitis, both antiseptics have proven successful as an adjunct to standard antibiotic therapy (7).

\section{Limitations of the Study}

The major limitations of this study are the small sample size, no randomization and no 
control arm. Larger prospective randomized placebo controlled studies are needed to confirm the obtained results.

\section{Conclusion}

The lysozyme-based oral spray was shown to be effective and safe in the reduction of pain, difficulty in swallowing and throat swelling in patients with acute tonsillopharyngitis associated with a common cold. Lysozymebased oral spray (containing natural compound with advantages of influencing immune system and preventing recurrences) had similar activity to benzydamine and chlorhexidine-based oral antiseptic sprays.

\section{What Is Already Known on this Topic \\ Bacterial resistance is one of the most significant problems in modern medicine. Although viruses are responsible for 85 - 95\% acute tonsillopharyngitis in adults, antibiotics are often prescribed for this indication contributing to increasing of an- timicrobial resistance and treatment costs. Local symptomatic treatment can be employed for reduction of symptoms of acute tonsillopharyngitis not associated with complications such as bacterial superinfection. There are many over-the-counter drugs which can be used for this purpose. Among them, lyso- zyme based preparations attract attention since it is a natural component of the human immunity (with activity against bac- teria, fungi, and viruses and anti-inflammatory effects). There are no data comparing efficacy and safety of lysozyme-based products versus other antiseptics in patients with an acute ton- sillopharyngitis associated with a common cold.}

\section{What this Study Adds:}

This study confirmed that lysozyme/cetylpyridinium/lidocaine oral spray is effective and safe in patients with acute tonsillopharyngitis. Moreover, lysozyme-based oral spray (containing natural compound with advantages of influencing immune system and preventing recurrences) had similar activity to benzydamine and chlorhexidine-based oral antiseptic sprays in the reduction of pain, difficulty in swallowing and throat swelling in patients with acute tonsillopharyngitis associated with a common cold.

Authors' Contributions: Conception and design: MM, BK, AŠ and JDž; Acquisition, analysis and interpretation of data: NGG, ZN, ZS and VČ; Drafting the article: MM; Revising it critically for important intellectual content: UG; Approved final version of the manuscript: NGG, ZN, ZS, AŠ, JDž, UG, BK, VČ and MM.
Conflict of Interest: Authors declare that this study was supported by Bosnalijek d.d. (a company which is the manufacturer of Lysobact COMPLETE Spray).

\section{References}

1. Graham J, Worrall GJ. An acute sore throat. Can Fam Physician. 2007;53(11):1961-2.

2. ESCMID Sore Throat Guideline Group. Guideline for the management of an acute sore throat. Clin Microbiol Infect. 2012;18(1):1-28.

3. Hedin K, Strandberg EL, Gröndal H, Brorsson A, Thulesius H, André M. Management of patients with sore throats in relation to guidelines: An interview study in Sweden. Scand J Prim Health Care. 2014;32(4):193-9.

4. Tewfik TL, Al Garni M. Tonsillopharyngitis: clinical highlights. J Otolaryngol. 2005;34(1): 545-9.

5. Farrer F. Sprays and lozenges for sore throats. S Afr Fam Pract. 2012;54(2):120-2.

6. Oxford JS, Leuwer M. Acute sore throat revisited: clinical and experimental evidence for the efficacy of over-the-counter AMC/DCBA throat lozenges. Int J Clin Pract. 2011;65(5):524.

7. Cingi C, Songu M, Ural A, Erdogmus N, Yildirim $\mathrm{M}$, Cakli $\mathrm{H}$, et al. Effect of chlorhexidine gluconate and benzydamine hydrochloride mouth spray on clinical signs and quality of life of patients with streptococcal tonsillopharyngitis: multicentre, prospective, randomized, double-blinded, placebo-controlled study. J Laryngol Otol. 2011;125(6):620-5.

8. Cioli V, Corradino C, Scorza-Barcellona P. Review of pharmacological data on benzydamine. Int J Tissue React. 1985;7(3):205-13.

9. Catic T, Mehic M, Binakaj Z, Sahman B, Cordalija V, Kerla A, et al. Efficacy and Safety of Oral Spray Containing Lysozyme and Cetylpyridinium: Subjective Determination of Patients with Tonsillopharyngitis. Mater Sociomed. 2016;28(6):459-63.

10. Kunel'skaia NL, Izotova GN, Luchsheva IuV, Voloshina IA, Artem'ev ME, Kudriavtseva IuS. Combined local therapy in oropharyngeal diseases. Vestn Otorinolaringol. 2008;(2):62-6.

11. Cingi C, Songu M, Ural A, Yildirim M, Erdogmus $\mathrm{N}$, Bal C. Effects of chlorhexidine/benzydamine mouth spray on pain and quality of life in acute viral pharyngitis: a prospective, randomized, double-blind, placebo-controlled, multicenter study. Ear Nose Throat J. 2010;89(11):546-9.

12. Sava G. Pharmacological aspects and therapeutic applications of lysozymes. EXS. 1996;75:433-49. 
13. Villa GT, Veiga-Crespo P. Enzybiotics: antibiotic enzymes as drugs and therapeutics. 1st ed. New York: Wiley; 2010.

14. Goncarova OB. The use of Lysobact in children who are often sick. Farmateka. 2007;17(7):63-6.

15. Van Driel ML, Sutter AS, Deveugele M, Peersman W, Butler CC, De Meyere M, et al. Are Sore Throat Patients Who Hope for Antibiotics Actually Asking for Pain Relief? Ann Fam Med. 2007;4(6):494-9.

16. Whiteside MW. A controlled study of benzydamine oral rinse ('Difflam') in general practice. Curr Med Res Opin. 1982;8(3):188-90.
17. Michel C, Salvatico S, Belkhelfa H, Haddioui L, Roques C. Activity of Drill ${ }^{\oplus}$ lozenges on the main microorganisms responsible for upper respiratory tract infections. Eur Ann Otorhinolaryngol Head Neck Dis. 2013;130(4):189-93.

18. Schapowal A, Berger D, Klein P, Suter A. Echinacea/sage or chlorhexidine/lidocaine for treating acute sore throats: a randomized, double-blind trial. Eur J Med Res. 2009;14(9):406-12. 